\title{
Avaliação das propriedades de intumescimento e permeabilidade de filmes isolados de polimetacrilato contendo polissacarídeo da raiz de Lótus (Nelumbo nucifera)
}

\author{
Claudia Renata Rosina, Silmara Baroni, Osvaldo Albuquerque Cavalcanti*
}

Laboratório de Tecnologia Farmacêutica, Departamento de Farmácia e Farmacologia, Universidade Estadual de Maringá

*Correspondência

O. A. Cavalcanti

Laboratório de Tecnologia

Farmacêutica, Departamento de

Farmácia e Farmacologia Universidade

Estadual de Maringá.

Av. Colombo, 5790, Anexo Bloco P02.

87020-900 Maringá - PR, Brasil

E-mail: oacavalcanti@uem.br
Polissacarídeo extraído da raiz de Lótus (Nelumbo nucifera) adicionado a polimetacrilato foi utilizado para a obtenção de filmes isolados, constituindo material candidato ao revestimento de formas farmacêuticas sólidas orais, sendo estas voltadas à liberação modificada de fármacos, potencialmente suscetiveis à degradação pela microflora presente exclusivamente na região distal do trato gastrintestinal. A adição do polissacarídeo ao polímero de base, dispersão aquosa Eudragit ${ }^{\circledR} S 30 D$, ocorreu em diferentes proporções: 100:0, 90:10, 80:20, 70:30. Os filmes isolados foram caracterizados pela determinação do indice de intumescimento e pela transmissão de vapor de água. Os resultados registraram, para as diferentes associações testadas, características de transparência (opacidade) e de flexibilidade alteradas e dependentes do aumento da concentração do polissacarídeo: 100:0>90:10>80:20>7030, o mesmo ocorrendo no tocante à permeabilidade ao vapor d'água. Todavia estas diferenças não foram significativas entre si, demonstrando manutenção das propriedades físico-químicas do polímero sintético contendo polissacarídeo, o que permite sugerir o material obtido como candidato potencial ao desenvolvimento de sistema para liberação colônica.

\section{INTRODUÇÃO}

O desenvolvimento de novos sistemas para liberação modificada de fármacos representa desafio constante na melhoria da qualidade dos tratamentos envolvendo medicamentos. A liberação específica de substâncias farmacologicamente ativas diretamente no sítio alvo, na dose necessária ao efeito esperado, constitui ferramenta tecnológica amplamente sugerida na diminuição dos efeitos colaterais advindos das elevadas doses e freqüentes administrações das formas farmacêuticas convencionais, em especial, daquelas voltadas ao tratamento de doenças gastrintestinais locais. Estas tecnologias sítio-específicas têm garantido o sucesso terapêutico de série de patologias, gerenciando a cinética de cedência dos fármacos de maneira controlada, além da proteção tanto dos princípios ativos frente aos fluídos digestivos, quando da mucosa gástrica (Bauer et al., 1998; Cavalcanti, Büttow, 1999; Cavalcanti et al., 2002). 
O colo, especialmente em seus segmentos iniciais, alças ascendente e transversa, poderá ser afetado por várias patologias, encontrando na liberação colônica específica, condição favorável ao sucesso terapêutico sem os episódios adversos desencadeados com aplicação dos sistemas convencionais. No desenvolvimento de sistemas para liberação colônica, os formuladores devem levar em consideração os obstáculos fisiológicos do trato gastrintestinal. Várias estratégias têm sido desenvolvidas utilizando essas características específicas existentes no colo tais como o $\mathrm{pH}$, a microflora, enzimas e o tempo de trânsito. Porém, é importante lembrar que esses parâmetros podem variar entre os indivíduos tanto pela dieta como por uma condição patológica. Ressalta-se, no entanto, que para alcançar maior efetividade farmacológica, esses sistemas devem garantir o transporte dos fármacos nas concentrações adequadas por toda trajetória pré-estabelecida, prevenindo a liberação prematura do conteúdo (Vandamme et al., 2002). Exemplo promissor da aplicação destas tecnologias é o desenvolvimento de sistemas terapêuticos contendo fármacos peptídicos, os quais são usualmente degradados na parte superior do trato gastrintestinal. Considerando-se que no colo a atividade proteolítica é reduzida, este segmento passa a ser um local potencial de absorção desses fármacos conforme descrito por Fertzner et al. (2004).

A microflora colônica é capaz de fermentar variedade de oligossacarídeos, dissacarídeos e polissacarídeos. O uso de materiais poliméricos naturais tem sido foco de grande interesse nas pesquisas voltadas ao desenvolvimento de novas formas farmacêuticas sólidas orais de liberação modificada. Os polímeros naturais (polissacarídeos e/ ou oligossacarídeos), devido às suas propriedades de baixa toxicidade, biodegradabilidade, características filmogênicas, facilidade de modificação estrutural, disponibilidade a baixo custo, têm se constituído em materiais de elevado interesse e destaque nas investigações voltadas à sua inclusão no grupo de excipientes farmacêuticos, conforme descrito na literatura (Gabas, Cavalcanti, 2003; Sinhá, Kumria, 2003; Hovgard, Brondsted,1996).

Dispersões aquosas formadas por polímeros sintéticos insolúveis denominadas pseudolátex são constituídas por derivados celulósicos ou acrílicos e encontram ampla aplicação no campo farmacêutico. A consagração histórica da aprovação destas dispersões pelos órgãos fiscalizadores e regulamentadores está aliada a sua ampla aplicabilidade no desenvolvimento de novos sistemas terapêuticos de ação modificada e, prioritariamente, no não comprometimento ambiental, aliado à extinção dos riscos de explosão apresentados pelos produtos contendo solventes orgânicos (Gabas, Cavalcanti, 2003). Associar polissacarídeos às dispersões aquosas de polímeros acrí- licos e/ou celulósicos, tem sido proposto na tentativa de combinar diferentes propriedades dos polissacarídeos, em especial, a vulnerabilidade à degradação específica, otimizando as consagradas características dos polímeros sintéticos no controle da liberação de fármacos, especialmente como candidatos à degradação específica no ambiente colônico (Cavalcanti et al., 2004). Combinar estes polímeros parece ser alternativa tecnológica extremamente atraente e promissora, uma vez que existe a possibilidade de diminuir a hidrofilia do sistema graças à combinação com polímeros insolúveis em quaisquer $\mathrm{pH}$ fisiológicos $\mathrm{e}$ aumentar a vulnerabilidade à cedência do fármaco com a presença de polissacarídeos utilizados como substratos pelas bactérias colônicas. Vários exemplos são contemplados na literatura científica: Gabas e Cavalcanti (2003) utilizaram goma arábica incorporada ao Eudragit ${ }^{\circledR} \mathrm{RS} 30 \mathrm{D}$; Cavalcanti et al.(2002) propuseram galactomanana $\mathrm{e}$ inulina adicionadas aos polimetacrilatos em base aquosa; Siew et al., (2004) propuseram a combinação amilose com etilcelulose; Wakerly et al., (1996) utilizaram a pectina adicionada a etilcelulose na formação de filmes; Vervoort e Kinget (1996) incorporaram a inulina ao Eudragit ${ }^{\circledR} \mathrm{RS}$. Todas essas pesquisas buscaram desenvolver materiais adequados à formação de filmes potencialmente colo-específicos.

Muitos polissacarídeos como, por exemplo, sulfato de condroitina, dextrana, amilose, arabinogalactana, arabinoxilana, amido, goma arábica, goma guar, tragacanta, amilopectina e pectina são fermentados pelas bactérias anaeróbicas residentes no colo humano, os quais podem ser aplicados como transportadores, possibilitando a liberação colônica de fármacos (Vandamme et al., 2002; Salyers et al., 1977).

O polissacarídeo arabinogalactana utilizado neste trabalho foi extraído da raiz da planta aquática Nelumbo nucifera, conhecida popularmente como raiz de Lótus, nativa da Ásia, sendo também bastante empregada na culinária. Sua flor é importante para muitas religiões orientais, já que é uma das plantas mais antigas do mundo, com sementes achadas há mais de 7000 anos.

A elevada hidrofilia comumente apresentada pelos polissacarídeos, em geral, constitui fator limitante da sua aplicação individual em sistemas voltados à liberação modificada de fármacos. Entretanto, com a combinação de polissacarídeos com polímeros caracterizados como materiais hidrofóbicos, a exemplo do Eudragit ${ }^{\circledR} \mathrm{RS} 30 \mathrm{D}$, poderse-á estrategicamente desenvolver ferramenta habilitada no desempenho de a liberação alvo- específica. O Eudragit ${ }^{\circledR} \mathrm{RS} 30 \mathrm{D}$ é um copolímero sintetizado a partir dos ésteres do ácido acrílico e metacrílico com número reduzido de grupos amônio quaternário, apresentando proprie- 
dades mecânicas, flexibilidade e características estéticas excelentes. A sigla 30D representa $30 \%$ de peso seco na dispersão, com densidade dos cátions de aminas de 1 para 40 unidades repetitivas de RS, e necessitam de plastificante para formação do filme (Lehmann, 1997). A inclusão do plastificante permite a redução da fragilidade e o aumento da elasticidade do filme, alterando as propriedades físicas e mecânicas do polímero (Gabas, Cavalcanti, 2003). Apresenta, também, a função de diminuir as forças intermoleculares entre as cadeias, melhorando, assim, a flexibilidade, a força tensil e as propriedades de adesão do filme formado. Este, ainda, solvata as cadeias poliméricas para diminuir a rigidez do filme e facilita a coalescência entre as cadeias, reduzindo, assim, a temperatura de formação de filme. Em geral, a concentração do plastificante aplicada está entre 1 a $50 \%$ do polímero hidrofóbico Eudragit ${ }^{\circledR}$ RS 30D (Lachman, Lieberman, Kanig, 2001). Alguns exemplos de compostos que podem ser utilizados com esta finalidade são: citrato de trietila (TEC) Citroflex ${ }^{\circledR}$, polietilenoglicol, PVP e monoestearato de glicerol.

O objetivo deste trabalho foi a obtenção de filmes isolados Eudragit ${ }^{\circledR} \mathrm{RS} 30 \mathrm{D}$ contendo o polissacarídeo de Nelumbo nucifera em diferentes concentrações. O processo de formação dos filmes foi desenvolvido aplicandose o método denominado "casting process", que consiste, basicamente, na evaporação do solvente aquoso e conseqüente coalescência das cadeias poliméricas formando filme contínuo. Sobre os filmes isolados das diferentes composições, realizamos determinação das taxas de transmissão de vapor d'água (TVA), assim como avaliação do índice de intumescimento (Ii\%). Apesar desses métodos de avaliação serem simples, são imprescindíveis na caracterização de materiais poliméricos candidatos ao revestimento farmacêutico. A associação do Eudragit ${ }^{\circledR}$ RS30D com polissacarídeo de Nelumbo nucifera foi investigada visando à identificação de composições viáveis para a confecção de filmes isolados, sendo esses potencialmente habilitados ao revestimento de formas farmacêuticas sólidas orais destinadas à liberação colônica.

\section{MATERIAIS E MÉTODOS}

\section{Materiais}

Raiz de lótus - Nelumbo nucifera (Lenkom Tamehiko Iwamoto Ltda, São Paulo/SP - Brasil), Eudragit ${ }^{\circledR} \mathrm{RS} 30 \mathrm{D}$ (copolímero metacrilato de amônio, tipo B, USP/NF/ Röhm Pharma, Darmstadt - Alemanha), citrato trietila (Morflex - EUA). Todos os outros materiais usados nos ensaios foram de grau analítico.

\section{Métodos}

\section{Extração do polissacarídeo}

A metodologia seguida para extração do polissacarídeo foi fundamentada no trabalho de Ramsdem e Bic (1998). O processo partiu de amostra pesando $500 \mathrm{~g}$ da raiz de lótus, sendo inicialmente triturada. Em seguida, foi desencadeado o processo de extração propriamente dito. O polissacarídeo foi extraído em água fria por turbólise a partir dos fragmentos da raiz de lótus. O produto da extração foi filtrado em funil de büchner com papel de filtro. Ao filtrado foram adicionados $5,85 \mathrm{~g}$ do $\mathrm{NaCl}$ para cada litro extraído, após agitação, para cada litro do extrato foram adicionados 2 litros de álcool $96^{\circ} \mathrm{GL}$, formando precipitado. A purificação do polissacarídeo foi realizada após filtração por adição de álcool absoluto, sendo, posteriormente, realizada filtração à pressão reduzida. Finalmente, ao produto foi adicionada acetona p.a. e concluindo o processo de purificação, realizamos nova filtração à pressão reduzida. O produto final foi deixado secar em estufa a $35^{\circ} \mathrm{C}$ durante um período de 24 horas.

\section{Preparação dos filmes}

Os filmes foram obtidos a partir de dispersões poliméricas de base aquosa preparadas em quatro diferentes concentrações, fazendo variar o polimetacrilato e/ou o polissacarídeo, permanecendo sempre a massa polimérica final de $4 \%(\mathrm{p} / \mathrm{v})$. As proporções de Eudragit ${ }^{\circledR} \mathrm{RS} 30 \mathrm{D}$ e de polissacarídeo extraído do Nelumbo nucifera foram, respectivamente: 100:0 (controle), 90:10; 80:20 e 70:30. O plastificante escolhido foi o citrato de trietila, adicionado na concentração de $20 \%$ em relação exclusivamente à massa polimérica do polimetacrilato.

O plastificante foi previamente incorporado na dispersão do polimetacrilato por agitação com tempo de 1 hora e, em seguida, foram preparadas diluições das dispersões aquosas dos dois polímeros nas 4 diferentes proporções. Dispersões contendo $4 \%(\mathrm{p} / \mathrm{v})$ do polissacarídeo foram previamente preparadas, sob agitação magnética (300 rpm), por 12 horas à temperatura ambiente de aproximadamente $25^{\circ} \mathrm{C}$. Alíquotas da dispersão do polissacarídeo foram adicionadas às dispersões de Eudragit ${ }^{\circledR} \mathrm{RS} 30 \mathrm{D}$, mantendo-se a massa final de $4 \%(\mathrm{p} / \mathrm{v})$. Após completa homogeneização dos constituintes em suas respectivas concentrações, foi retirado o ar incorporado às dispersões pelo processo de agitação utilizando bomba de vácuo. Finalmente, foram colhidas amostras $(10,0 \mathrm{~mL})$ representantes das diferentes composições e vertidas em moldes previamente demarcados em placa de Teflon ${ }^{\circledR}$. Após 15 horas na estufa na temperatura de $60{ }^{\circ} \mathrm{C}$, os filmes foram cuidadosamente removidos do substrato e re- 
alizou-se avaliação macroscópica, visando desprezar filmes que apresentavam rachaduras, bolhas ou imperfeições. Em seguida, foi determinada a espessura dos filmes usando-se micrômetro (Mitutoyo ${ }^{\circledR} n^{0} 2046$ - Japão) em 4 pontos aleatórios da superfície. As membranas selecionadas foram acondicionadas em dessecadores até o momento da realização dos experimentos.

\section{Determinação do Índice de Intumescimento (li\%)}

Os filmes das diferentes associações propostas foram cortados com aproximadamente $1,0 \mathrm{~cm}^{2} \mathrm{e}$, em seguida, distribuídos no interior de placas de Petri. Posteriormente, as placas de Petri foram colocadas em estufa a $70^{\circ} \mathrm{C}$, por, aproximadamente, 15 horas, visando determinar a perda total de umidade. Após este tempo, as placas foram retiradas e mantidas em dessecadores durante a realização do experimento. As amostras das diferentes associações foram pesadas em balança analítica, imediatamente imersas em recipientes contendo água e mantidas por diferentes intervalos de tempo à temperatura ambiente. Cumpridos os intervalos de tempo pré-estabelecidos, as amostras foram removidas dos meios com auxílio de pinça e cuidadosamente enxugadas entre duas folhas de papel de filtro e repesadas. O mesmo procedimento foi adotado para todas as outras amostras mantidas por períodos correspondentes aos intervalos de 1 a 10,30 e 60 minutos de imersão, conforme metodologia citada por Cavalcanti et al. (2002).

Para o cálculo do índice de intumescimento (Ii\%) foi utilizada a seguinte equação:

$$
\text { Ii } \%=\frac{\text { Peso final }- \text { Peso inicial }}{\text { Peso final }} \times 100
$$

\section{Determinação da Transmissão de Vapor d'água (TVA)}

O estudo de TVA foi desenvolvido de acordo com método B da ASTM (American Society for Testing and Materials) designado E96-66, conforme citado por Gabas e Cavalcanti (2003). Inicialmente, no interior de cada cúpula de permeabilidade (modelo Payne permeability cup, Braive Instruments, Liege, Bélgica) foram adicionados 10,0 mL de água destilada. Em seguida, os filmes a serem investigados, com diâmetro adequado $( \pm 5,5 \mathrm{~cm})$, foram fixados às cúpulas individualmente. $\mathrm{O}$ conjunto (cúpula+água destilada + filme) foi pesado e armazenado no dessecador contendo sílica-gel. O dessecador foi deixado à temperatura e umidade ambientes. As cúpulas, em triplicata para cada associação, foram pesadas nos intervalos de $0,24,48,72$ e 96 horas. A cada intervalo de tempo pré-estabelecido a sílica-gel foi permutada por outra desidratada. Os pesos perdidos pelas cúpulas nos respectivos intervalos de tempo foram registrados e aplicados para calcular a taxa de transmissão de vapor d'água transportada através das membranas (Cavalcanti et al., 2002).

\section{Análise estatística}

Os resultados dos ensaios obtidos a partir da determinação do índice de intumescimento, assim como, de transmissão de vapor d'água para as três diferentes concentrações (90:10; 80:20 e 70:30), quando comparadas com o controle (100:0), foram expressos como média \pm erro padrão da média (epm) e estudados pela análise de variância (ANOVA) para múltiplas comparações. $\mathrm{P}<0,05$ foi utilizado como nível de significância.

\section{RESULTADOS E DISCUSSÕES}

As diferentes composições investigadas neste trabalho proporcionaram formação de filmes isolados adequados aos ensaios. Baseados nas características macroscópicas dos filmes formados, a presença do plastificante escolhido parece não ter interferido na compatibilidade dos componentes nas formulações propostas, especialmente em relação ao polissacarídeo escolhido. O interesse pelo aumento na concentração do polissacarídeo objetivou proporcionar produção de material filmogênico detentor de maior vulnerabilidade à fermentação específica no ambiente colônico. Entretanto, os filmes contendo Eudragit ${ }^{\circledR} \mathrm{RS} 30 \mathrm{D} /$ polissacarídeo passaram a apresentar características de transparência (opacidade) e de flexibilidade alteradas e dependentes do aumento da concentração do polissacarídeo: 100:0>90:10>80:20>7030. Os ensaios de determinação do índice de intumescimento demonstraram, conforme registrado na Figura 1, que apesar das alterações registradas, houve um período de equilíbrio da hidratação para todos as composições entre 10 e 20 minutos. A análise estatística (ANOVA) sobre o conjunto dos dados gerados nos experimentos realizados demonstrou que, apesar das alterações observadas, todas vinculadas à participação do polissacarídeo, não se registraram diferenças significativas $(\mathrm{p}>0,05)$ entre as composições, quando comparadas ao controle. Aqui vale salientar que melhor hidratação foi obtida, sendo esta proporcional à presença do polissacarídeo. Este fator é considerado extremamente positivo, uma vez que a acessibilidade para degradação bacteriana no ambiente colônico necessita de hidrofilia moderada das películas de revestimento (Van den Mooter, Samyn, Kinget, 1994; Cavalcanti et al., 2002).

Conforme podemos constatar na Figura 2, observamos, também, ter havido moderadas alterações na permeabilidade dos filmes isolados testados, sendo estas 


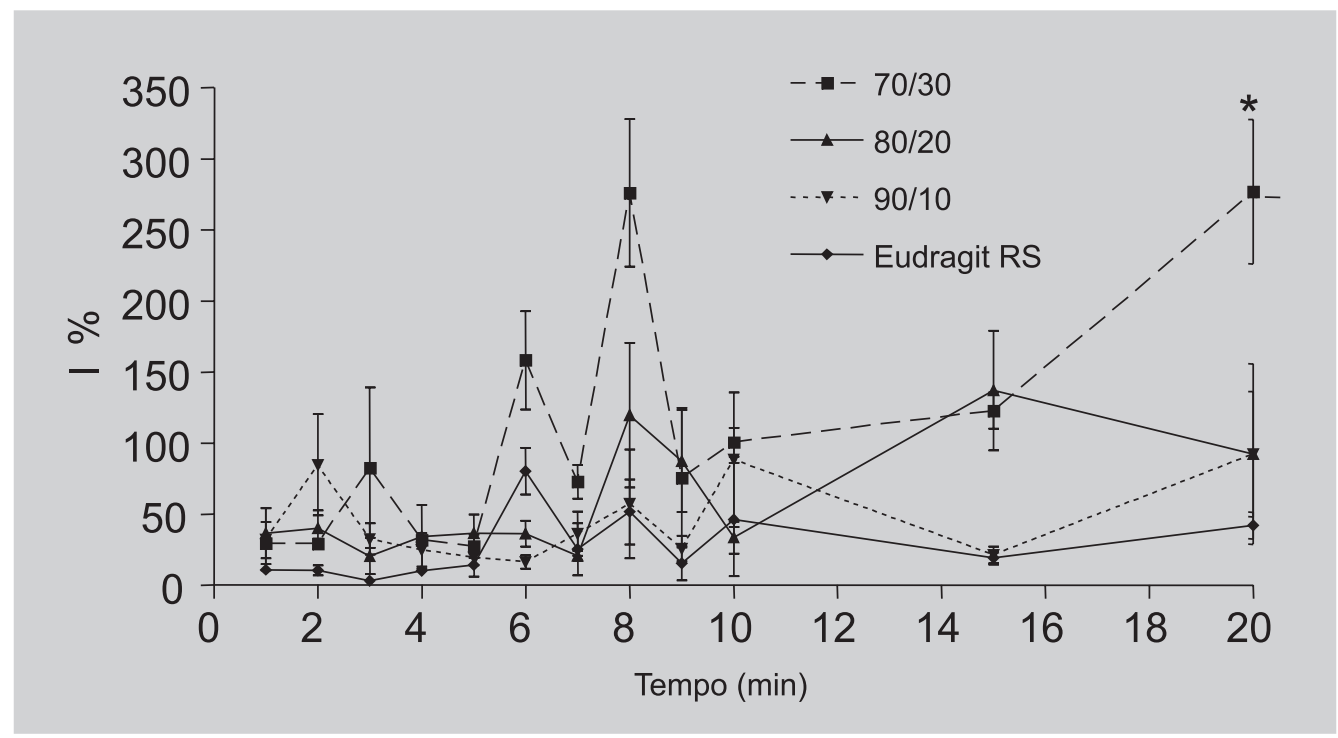

FIGURA 1 - Índice de intumescimento (I\%) em água dos filmes nas diferentes associações - Eudragit ${ }^{\circledR} \mathrm{RS}$ 30D/polímero extraído da raiz de Nelumbo nucifera $(\mathrm{n}=3)$.

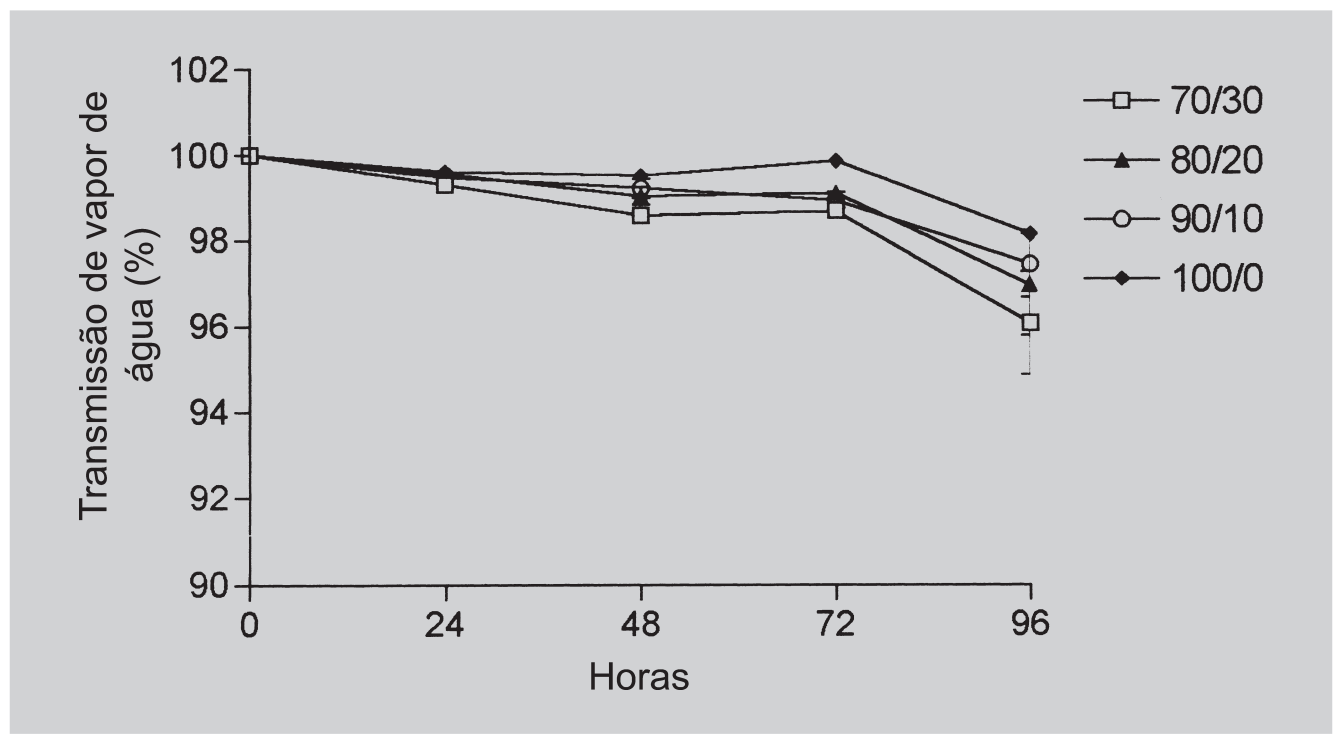

FIGURA 2 - Transmissão de vapor de água dos filmes nas diferentes associações - Eudragit ${ }^{\circledR}$ RS 30D/polímero extraído da raiz de Nelumbo nucifera $(\mathrm{n}=3)$.

dependentes e proporcionais à presença do polissacarídeo. Observou-se que a permeação de vapor d'água foi alterada e dependente da concentração do polissacarídeo incorporado, provavelmente correspondendo ao aumento na hidrofilia do sistema. Gabas e Cavalcanti (2003), trabalhando com filmes isolados de Eudragit ${ }^{\circledR} \mathrm{RS} 30 \mathrm{D}$ contendo goma arábica, registraram aumento proporcional e dependente dos valores de hidratação e da taxa de transmissão de vapor d'água proporcionais ao aumento de concentração do polissacarídeo incorporado. Em outro trabalho Cavalcanti et al. (2002), trabalhando com Eudragit ${ }^{\circledR} \mathrm{RS} 30 \mathrm{D}$ associado a galactomanana ou a inulina, observaram semelhante comportamento na permeabilidade, proporcional ao aumento da concentração do polissacarídeo. Nossos resultados podem ser considerados satisfatórios frente à etapa atual da pesquisa, prioritariamente por não ter havido diferenças significativas em nossos resultados entre as combinações testadas, prevalecendo as características do polímero de base, ou seja, Eudragit ${ }^{\circledR} \mathrm{RS} 30 \mathrm{D}$, polímero consagrado na fabricação de sistemas para liberação modificada de fármacos. Ensaios envolvendo meios de simulação dos fluídos do trato gastrintestinal deverão indicar qual 
das composições poderá ser candidata à aplicação posterior em substratos sólidos para uso oral.

\section{CONCLUSÃO}

Os resultados deste estudo indicaram que o polissacarídeo extraído da raiz de Lótus, quando incorporado ao Eudragit ${ }^{\circledR} \mathrm{RS} 30 \mathrm{D}$ na formação de filmes isolados, forneceu subsídios iniciais promissores quando à perspectiva da aplicação deste material no desenvolvimento de um sistema voltado à liberação colo-específica. Os valores registrados relacionados à hidratação, assim como, à permeabilidade, encontraram dependência no aumento da participação do polissacarídeo, gerando filmes mais permeáveis e com maior grau de hidratação, quando comparados ao controle 100\% de Eudragit ${ }^{\circ} \mathrm{RS} 30 \mathrm{D}$. O aumento, mesmo que limitado, sugere a produção de uma composição com níveis de hidrofilia satisfatórios à acessibilidade para degradação específica no segmento distal do trato digestivo. Esses resultados nos permitem sugerir que os filmes isolados produzidos neste trabalho poderão, após estudos complementares, ser utilizados para revestimento de comprimidos ou cápsulas para liberação colo específica.

\section{AGRADECIMENTOS}

Os autores agradecem à professora Dra. Marli Miriam de Souza Lima, do Laboratório de Farmacotécnica da Universidade Estadual de Maringá, pelo auxílio no processo de extração, isolamento e purificação do polissacarídeo da raiz de Nelumbo nucifera. Agradecem, também, à empresa Almapal (São Paulo/SP), pelas amostras dos produtos Eudragit ${ }^{\circledR}$ RS30D (Rohm Pharma, Alemanha) e citrato de trietila (Morflex - EUA).

\section{ABSTRACT}

\section{Evaluation of swelling and permeability properties of films isolated from polymethacrylate containing polysaccharide from Lotus root (Nelumbo nucifera)}

Polysaccharides such as extracted from Lotus root (Nelumbo nucifera) combined with polymethacrylates on isolated films for film coating was studied as potential vehicles for colonic drug delivery, susceptible to fermentation by micro flora. For the preparation we used the association of Eudragit ${ }^{\hat{a}} R S$ $30 D$ and polysaccharides in different concentrations (100:0, 90:10, 80:20, 70:30) in aqueous-based solvents. In the present study, the films were characterized by swelling studies and water vapor transmission studies. These tests demonstrated that different associations do not present significant differences, showing that the physico-chemical properties of Eudragit ${ }^{\circledR} R S 30 D$ are not altered and this material will be able to be applied for film formation in coating for colonic drug delivery system development.

UNITERMS: Polysaccharides. Nelumbo nucifera. Polymethacrylates. Colonic drug delivery.

\section{REFERÊNCIAS BIBLIOGRÁFICAS}

BAUER, K.H.; LEHMANN, K.; OSTERWALD, H.P.; ROTHGANG, G. Coated pharmaceutical dosage forms. Florida: CRC Press, 1998. p. 123-126.

CAVALCANTI, O.A.; BUTTOW, N.C. Perspectivas dos sistemas de liberação colo-específicos. Arq. Ciênc. Saúde Unipar, Umuarama, v. 3, n. 3, p. 227-238, 1999.

CAVALCANTI, O.A.; VAN DER MOOTER, G.; CARAMICO-SOARES, I.; KINGET, R. Polysaccharides as excipients for colon-specific coatings, permeability and swelling properties of casted films. Drug Dev. Ind. Pharm., New York, v.28, n 2, p. 157-164, 2002.

CAVALCANTI1; O.A.; PETENUCI, B., BEDIN; A. C., PINEDA, E. A. G., HECHENLEITNER, A. A. W. Characterization of ethylcellulose films containing natural polysaccharides by thermal analysis and FTIR spectroscopy. Acta Farm. Bonaerense, La Plata, v. 23, n. 1, p. 53-57, 2004.

FERTZNER, A.; BÖHM, S.; SCHREDER, S.; SCHUBERT, R. Degradation of raw or film incorporated bðcyclodextrin by enzymes and colonic bacteria. Eur. $J$. Pharm. Biopharm., Amsterdam, in press.

GABAS, V.G.S.; CAVALCANTI, O.A. Influência da adição de goma arábica em filmes isolados de polímero acrílico. Estudo das propriedades de intumescimento e de permeabilidade. Rev. Bras. Ciên. Farm., São Paulo, v.39, n.4,p. 441-448, 2003.

HOVGAARD, L.; BRONDSTED, H. Current applications of polysaccharides in colon targeting. Crit. Rev. The. Drug Carrier Syst. Boca Raton, v. 13, n.3-4, p.185-223, 1996. 
LACHMAN, L.; LIEBERMAN, H. A.; KANIG, J.L. Teoria e prática na indústria farmacêutica. Lisboa: Fundação Calouste Gulbenkian, 2001. p. 599-649.

LEHMANN, K. O. R. Chemistry and application properties of polymethacrylates coating systems. In: Mc GINITY, J. W. Aqueous polymeric coatings for pharmaceutical dosage forms, New York: Marcel Dekker., 1997. cap. 4, p. 101-176.

RAMSDEN, L.; BIC, W.Y. Polyssaccharides of Lótus root. Trop. Agric., Trinidad and Tobago, v. 75, p. 288-290, 1998.

SALYERS, A. A.; WEST, S.E.; VERCELOTTI, J.R. WILKINS, T.D. Fermentation of mucins and plant polysaccharides by anaerobic bacteria from the human colon. Appl. Environ. Microbiol., Bedford, v. 34, n. 5, p. 529-533, 1977.

SIEW, L. F.; MAN, S-M; NEWTON, J.M.; BASIT, A.W. Amilose formulations for drug delivery to the colon: a comparison of two fermentation models to asses colônica targeting performance in vitro. Int. J. Pharm., Amsterdam, v. 273, n.1-2, p. 129-134, 2004.
SINHA, V. R.; KUMRIA, R. Coating polymers for colon specific drug delivery: A comparative in vitro evaluation. Acta Pharm., Zagreb, v.53, n.1, p.41-47, 2003.

VANDAMME, T.F.; LENOURRY, A.; CHARRUEAU, C.; CHAUMEIL, J.C. The use of polysaccharides to target drugs to the colon. Carb. Polym., Oxford, v.48, n.3, p.219-231, 2002.

VAN DEN MOOTER, G.; SAMYN, C.; KINGET, R. Characterization of colon-specific azo polymers: A study of the swelling properties and the permeability of isolated polymer films. Int. J. Pharm., Amsterdam, v. 111, n.2, p.127-136, 1994.

VERVOORT, L., KINGET, R. In vitro degradation by colonic bacteria of inulinHP incorporated in Eudragit RS films. Int. J. Pharm., Amsterdam, v.129, n.1-2, p.185-190, 1996.

WAKERLY, Z.; FELL, J.T.; ALTTWOOD, D.; PARKINS D. Pectina/ethylcellulose film coating formulations for colonic drug delivery. Pharm. Res., New York, v.13, n.8, p. 1210-1212, 1996.

Recebido para publicação em 29 de junho de 2004. Aceito para publicação em 29 de setembro de 2004. 